\title{
Online Therapy for Addictive Behaviors
}

\author{
MARK GRIFFITHS, Ph.D.
}

\begin{abstract}
Clinicians working in the field of addictive behaviors cannot afford to ignore the Internet. Psychological advice, help, and treatment for addicts are no exceptions, with both counseling and psychotherapy entering the computer age. This paper reviews the main issues in the area and approaches the discussion acknowledging that online therapy has to be incorporated within the overall framework of the need for clinical assistance. The paper also provides brief overviews of some websites as illustrative examples of what types of online therapy are available.
\end{abstract}

\section{INTRODUCTION}

$\mathbf{M}$ OST THERAPISTS remain suspect about the new and growing field of "behavioral telehealth." For instance, some have claimed that Internet therapy is an oxymoron, because psychotherapy is based upon both verbal and nonverbal communication. ${ }^{1}$ It could be argued that since online relationships are just as real and intense as those in the face-to-face world, ${ }^{2}$ there is little surprise that clinicians are beginning to establish online therapeutic relationships. Others may argue that the time has come to embrace the new technology and to carry out research into this potentially innovative form of therapy.

To date there have been a growing number of non-empirical papers about various issues concerning online therapy including challenges and initiatives in this growing field, ${ }^{3,4}$ ethical issues, ${ }^{5}$ mediation of guidance and counseling using new technologies, ${ }^{6}$ and perspectives on family counseling. ${ }^{7,8}$ There have also been a growing number of empirical reports utilising online therapy. These include its use in treating anxiety and panic disorders,, 10 eating disorders, ${ }^{11-14}$ post-traumatic stress disorder, 15 and individuals with recurrent headaches. ${ }^{16}$ Every one of these empirical studies showed significant improvements for those treated using online therapy.

\section{Online therapy and addictive behavior}

For the third time in four days, a 32-year-old woman comes home very late from a 14-hour drinking session. Unable to sleep, she logs onto the Internet and locates a self-help site for alcoholics and fills out a 20-item alcohol consumption checklist. Within a few hours she receives an e-mail which suggests she may have an undiagnosed drinking disorder. She is invited to revisit the site to learn more about her possible drinking disorder, seek further advice from an online alcohol counselor and join an online alcoholism self-help group.

On initial examination, this fictitious scenario appears of little concern until a number of questions raise serious concerns. ${ }^{17}$ For instance, who scored the test? Who will monitor the self-help group? Who will give online counseling advice for the alcohol problem? Does the counselor have legitimate qualifications and experience regarding alcohol problems? Who sponsors the website? What influence do the sponsors have over content of the site? Do the sponsors have access to visitor data collected

Psychology Division, Nottingham Trent University, Nottingham, United Kingdom. 
by the website? These are all questions that may not be raised by an addict in crisis seeking help.

The Internet could be viewed as just a further extension of technology being used to transmit and receive communications between the helper and the helped. If addiction practitioners shun the new technologies, others who might have questionable ethics will likely come in to fill the clinical vacuum. Online therapy is growing and appears to be growing at exponential rates. ${ }^{1}$ Furthermore, its growth appears to outstrip any efforts to organise, limit and regulate it. It has been claimed that online therapy is a viable alternative source of help when traditional psychotherapy is not accessible. Proponents claim it is effective, private and conducted by skilled, qualified, ethical professionals. ${ }^{7}$ It is further claimed that for some people, it is the only way they either can or will get help (from professional therapists and/or self-help groups).

\section{Types of online therapy}

There appear to be three main types of website where psychological help is provided-information and advice sites, websites of traditional helping agencies and individual therapists. ${ }^{4}$ In this paper, however, sites will be categorized in terms of their primary function: (1) information dissemination, (2) peer-delivered therapeutic/support/advice (such as a self-help support group), and (3) professionally delivered treatment. Psychological services provided on the Internet range from basic information sites about specific disorders, to self-help sites that assess a person's problem, to comprehensive psychotherapy services offering assessment, diagnosis, and intervention. ${ }^{17}$

Information dissemination. These are sites mainly dedicated to educational and consciousness raising issues. They are often in the form of WebPages, which provide easily understandable pieces of helpful information on a range of disorders, selfhelp checklists, and links to other helpful websites. There appear to be numerous places to get information about addiction and addiction-related problems. Quality information websites are hosted by a variety of sources including individuals who serve as their own "webmaster" to not-for-profit organisations to private companies. Some illustrative examples of these are listed in the next section.

Peer-delivered therapeutic support and advice. These sites are often set up by traditional helping agencies that have expanded their services to include an online option for clients. Typically, this is done by e-mail and is usually free of charge (e.g., the Samaritans). Other examples include various 12-Step groups who meet online. Many online therapy services are available for those suffering almost any kind of addiction. In the world of online therapy a person can be alone in their living room while they attend an AA meeting joined by a couple of dozen people from various countries, or be visiting an Internet counselor in the United States without having left their home in Australia. There are a number of 12-Step groups that meet regularly in this way, and they are often open for 24-h a day. Most of these sites are listed in the AA's "Big Book" website <www.aabigbook.com>.

There are a number of very good reasons why the Internet is an excellent medium for most forms of self-help. For instance, research has consistently shown that the Internet has a disinhibiting effect on users and reduces social desirability (i.e., users do not alter their responses in order to appear more socially desirable). ${ }^{18}$ This may lead to increased levels of honesty and, therefore, higher validity in the case of self-disclosure. ${ }^{19}$ As well as disinhibition effects, the Internet is a non-face-to-face environment that is perceived by many users to be anonymous and non-threatening. The Internet may, as a consequence, provide access to "socially unskilled" individuals who may not have sought help if it were not for the online nature of the self-help group.

There are also generalist type services (usually e-mail only) in which people usually require a oneoff piece of advice from someone who may have no psychological training. These services are usually (but not always) free of charge and may be part of an online magazine. It is highly unlikely that the sort of general advice given at these sites will be of much help to addicts as their problem is, by its nature, very specific. The most help they would probably get is an onward referral (e.g., to a face-to-face self-help group such as AA, GA). This is somewhat different from online peer-support groups who meet either in an asynchronous (letters sequentially posted to an electronic discussion list/bulletinboard in the order they are received by the webmaster) or synchronous (in real time as with live chat rooms) manner.

Professionally delivered treatment. These sites are becoming more and more abundant and can be set up by individual counselors and/or psychotherapists. They usually operate in one of two ways-either by written answers to e-mail inquiries or a real time conversation in an Internet "chat room." An obvious question to ask is why do people engage in online therapy? In comparison with other media 
(face-to-face, telephone), the Internet offers perceived anonymity and people can use e-mail addresses which are very difficult if not impossible to trace back to the user. However, some benefit may simply be the outpouring of written emotions which might equally be achieved by handwriting an unseen missive. Professionally delivered treatment mainly seems to be available from individual practitioners' websites. There are a few examples of not-for-profit organisations beginning to offer these types of services. Thus far, for-profit companies appear to primarily use the Internet for information dissemination and for promoting their face-to-face services.

Almost anybody can host a website if they have a computer and associated software: from the neophyte to computer expert, from the individual in recovery to large organizations. Increasingly, many consumer-authored sites are very credible in terms of their content and professional looking in terms of their appearance. Of course, the skill needed is to be able to tell when inaccurate (or even potentially harmful) information is being made available. However, discerning what is appropriate or inappropriate is much more challenging to do when a recipient of information, advice or counseling is receiving such privately. However, this can also be said of a face-to-face service too. There are numerous instances of inappropriate information being given by professionals/peers and numerous improprieties. Many jurisdictions do not have quality assurance mechanisms in place to ensure that those indicating a certain level of competency are indeed practicing at that level.

Many therapists have now set up their own Internet sites to deliver behavioral services although the number of sites that specialize in addictions appears to be growing all the time. The kinds of services offered vary in type and expense. They can include "ask five questions for free"-type sites, therapists moderating a group chat online, e-mail correspondence, private instant messaging, or video-conferencing (Table 1). There are many advantages and disadvantages of online therapy although these will not be outlined here as they have been extensively overviewed elsewhere. ${ }^{4}$

\section{ILLUSTRATIVE EXAMPLES}

Anyone typing "addiction" and "online therapy" or "online counseling" into a search engine will find hundreds of websites offering to provide help. In this section, some of these websites are briefly examined to inform the reader of the ser- vices available, who it is aimed at, and the types of service that are provided. The author does not personally endorse any of the listed sites and is only highlighting them for illustrative purposes only.

\section{Websites delivering professional treatment}

There are hundreds of organizations and individuals who offer online therapy of some description. As can be seen below, the types of service available differ from site to site in the exact specifics of what is offered. The sites chosen below were selected due to their slightly different emphases and approached to online treatment and are in no particular order.

- <www.asktheinternettherapist.com/>. This website provides a variety of different online counseling alternatives such as telephone therapy, e-mail counseling, chat therapy, and audiovisual therapy. Their staff are "fully qualified" Internet counselors and mental health counseling professionals specialising in a number of areas including e-therapy and substance abuse counseling. Their therapeutic goal is to treat the whole person and they have facilities to provide online therapy sessions with several specialists simultaneously or individually.

- <www.addictionrecoveryguide.org/treatment/ online.html>. This website provides treatment services for alcohol and drug addiction by "trained experts via the Internet." They claim they have the potential to bring treatment to individuals who are unable to access traditional treatment programs or who want to strengthen recovery after completing a traditional treatment program. They claim their service provides many of the benefits of traditional treatment approaches, including group sessions led by addiction counselors, peer support and psychoeducational tools for recovery.

- Reach Today <www.reachtoday.com:gt;. This website was developed by a "certified addiction counselor" offering online services incorporating email and instant messaging. The site claims e-counseling is a easy accessible and costeffective way to engage in therapy or counseling from a distance. Clients gain access to an addiction counselor for feedback and support, and their services include initial inquiry, brief consultation (single session), or extended e-counseling.

- Choose 2 Change <www.choose2change.com>. This website has an online substance abuse counseling program that includes individualised professional counseling services provided 
Table 1. Types of Online Counseling Service Sites (Adapted and Expanded from Connall23)

"Ask-a-question"

This is basically where a person will write to a counselor with a specific problem and will then receive a customized answer.

Positive: This is good if there is a well-defined problem that is succinct and to the point.

Negative: It is bad if the nature of the problem is very complex and has occurred over a protracted period of time.

Ongoing private chat

This is basically where a client "chats" with a counselor through the use of an instant messaging system (usually for a pre-defined period, such as an hour).

Positive: This is more likely to be beneficial if the issues are non-traumatic (relationship issues, job stress) and the client enjoys writing.

Negative: This is unlikely to be of much benefit if the person is suffering from a severe or chronic problem (depression, addictions of various kinds, trauma), as body language and facial cues can be critical for the counselor to do an effective job.

Via e-mail

This is basically where the client corresponds with the counselor using e-mail messages.

Positive: This can be of benefit if the client wants to "unload" at any time. It can also be used as an adjunct to traditional therapy in which the client and the counselor can maintain contact long after the end of the formal session.

Negative: This method is unlikely to be of benefit if the client does not like writing about their problems at length.

Support groups with a counselor

This is basically where people can go to designated "chat rooms" and talk with other like-minded individuals about their problems in a supportive online environment. These discussions are usually overseen and facilitated by professionals.

Positive: If a person feels alone with a problem, sharing the problem in a group setting can be a liberating experience. The person can benefit from immediate feedback from other group members in a non-threatening (i.e., non face-to-face) environment. This is also very advantageous to those without access to fellow sufferers.

Negative: Online support groups raise many ethical and legal issues as anyone logging on (e.g., minors) can log on and lie about their situation, age, and/or identity

Video-conferencing

As with face-to-face private sessions, the client will "meet" with the counselor for designated periods of time and see and hear each other through cameras.

Positive: This is beneficial if a person wants the counselor to be able to fully evaluate them.

Negative: Despite visual presence, the visual presentation can still be poor (although this is getting better all the time).

by "licensed counselors and supervised interns." The program provides an online social/educational program for the recovery from alcohol and drug addiction. Treatment plans are tailored for each participant and are based on a thorough assessment of each person's specific needs and goals. Progress is assessed regularly by the counselor as part of the long-term commitment to the recovery program. In addition to individualised sessions with a counselor, integrated online group sessions are available to support the social and interpersonal communication needs of participants.
- EGetGoing <www.egetgoing.com>. This website provides online chemical dependency treatment using "advanced telemedicine and e-learning technologies." It provides online, realtime interactive audio- and video-based substance abuse treatment. In an interactive setting, group members talk to each other under the guidance of an experienced counselor who uses a treatment approach that is based on the 12-Step philosophy. Two programs are available: Lifeline (Internet-based outpatient treatment) and Living (an Internet-based continuing care program). Groups meet twice a week at regularly sched- 
uled times for $1 \mathrm{~h}$. Each treatment and continuing care session follows a format designed to address a particular topic area. Sessions present information on relapse prevention, the medical aspects of addiction, anger management and other topics. Eighty percent of group time is spent in discussion, supported by interactive multimedia tools such as video dramatisations, interactive slides, private chat, and more. Developed for people who are new to recovery or who are returning after a relapse, Primary Treatment has 24 sessions over 12 weeks and Basic Group has 12 sessions over 6 weeks. Aftercare treatment includes an Intensive Aftercare Program that meets twice a week for 12 weeks and Basic Aftercare that meets once a week for 12 weeks. Each group member is provided with a secure and private personal home page that affords access to such tools as personal e-mail, personal journal, and homework assignments.

- Self-help works.com <www.selfhelpworks.com>. This website offers cognitive-based learning programs that explore the causes of problem behaviors and provide training on how to change them. The programs are delivered via the Internet as a series of lectures and interactive assignments. Each course lasts from three to five weeks. During the first week participants visit the site almost daily. Thereafter, visits are twice per week. Most sessions require completing an assignment and reading additional site materials. Each session takes approximately $1 \mathrm{~h}$. A schedule is provided and emails are sent to remind participants of their next scheduled session.

- The Camp Recovery Center <www.camprecovery.com/online_treatment.asp $>$. This website includes Internet-based primary treatment and continuing care. The CRC has a partnership with eGetgoing and combines traditional group treatment methods with the Internet technology to provide live, interactive, group treatment, and continuing care online. During primary treatment, clients participate in groups online supervised by an "experienced Addiction counselor." Relapse prevention groups are held weekly and clients have the opportunity to interact with others in the process of recovery.

- TeenGetGoing <www.teengetgoing.com>. This website is an online substance abuse treatment program geared to the needs of adolescents. In addition to educational information on alcohol and drugs, teenagers can join online treatment groups. Two programs are available. The Adolescent Group Treatment Program has 24 live group sessions online facilitated by "an experienced counselor." These scheduled groups have 8-10 members and meet online twice a week to provide a full treatment program. The Awareness Program is a 12-session assessment and prevention program that teenagers can take on their own and does not have a live counselor or live group interactions.

\section{Websites providing (mostly) information dissemination}

There are countless information dissemination sites on the Internet many of which are aimed at adolescents or their parents. Below are some illustrative examples:

- Day-By-Day.org <www.day-by-day.org>. This website is geared to providing online resources for young people with addictions. The web site features "Super Sober Sites" (sites that motivate and support young people to get clean and sober and to maintain their sobriety), online recovery tools such as "Young People in AA," "Poetry for Recovery," "Fun and Leisure for Recovery," and "Listen for Recovery," chat rooms, and forums for young people.

- Freevibe.com <www.freevibe.com>. This website provides a variety of information on drugs and their risks. The section on 'Drug Facts' provides scientific information about illegal drugs and their effects including crack/cocaine, inhalants, ecstasy, marijuana etc. The site also has a "Share your Story" message board, a multimedia presentation on 16 drugs, including what they are, what they do and body facts, an "In the News" section, and a further links section.

- Project GHB <www.projectghb.org>. This educational website was formed to increased awareness about the dangers of GHB (Gamma hydroxy butyrate), also known as "G," Liquid E, Fantasy, Liquid X, Liquid Ecstasy, Organic Quaalude, and Jib among other names. The site covers facts about GHB including its effects, signs of overdose, and adverse reactions. It also provides information on treatment, a section for reporting serious events, a newsletter, resource links, and legal issues.

- National Youth Network <www.nationalyouth. com/substanceabuse.html >. This website serves as a resource for youths, parents, and professionals, by providing education and information on programs and services available for adolescents with substance abuse and other emotional/behavioral problems. The range of services include online self-help and assessment information, 
telephone assessments with "a masters level clinician," and directories of therapeutic options including wilderness programs, outdoor therapy, boarding schools, therapeutic boarding schools, residential treatment centers, nonpublic day schools, outpatient and day treatment, and summer camps and programs.

- The AA Big Book <www.aabigbook.com>. This website offers a large directory of the official websites of almost every 12-Step "Anonymous" group in the United States and world (e.g., Alcoholics Anonymous, Narcotics Anonymous, Gamblers Anonymous). The site offers links to places where addicts can exchange messages with other people suffering from similar addictions. The site offers links to information about sex addiction, gambling addiction, overeating, and cigarette smoking.

\section{FUTURE DIRECTIONS}

Online therapy may not be for everyone, and those participating should at the very least be comfortable expressing themselves through the written word. In an ideal world, it would not be necessary for those in serious crisis-some of whom could be addicts (where non-verbal cues are vital) — to need to use computer-mediated communication-based forms of help. However, because of the Internet's immediacy, if this kind of therapeutic help is the only avenue available to individuals and/or the only thing they are comfortable using, then it is almost bound to be used by those with serious crises.

The problem with online therapy is that there are so many different types and much of it could be of poor quality. At best the industry is self-regulated and at worst completely unregulated (although it must be noted that this is not unique to Internet sites). Rigorous evaluation studies are needed (particularly given the rate at which new sites are springing up). These refer not only to sites that specifically deal with addictions, but all sites.

It could be the case that online therapy's most effective use might be as either a way of communicating information in response to clients' statements and questions, or a form of "pre-therapy." This latter suggestion is interesting as it has traditionally been assumed that for "pre-therapy" to occur, the client and practitioner had to be in the same room. However, it could equally be argued that websites could be used to augment treatment. Websites could provide cognitive information to supplement treatment or provide instant peer support groups when addicts need most help. For in- stance, chat rooms can be used by addicts desiring a more secure anonymity than is possible at a public 12-Step meeting. Furthermore, public message boards and e-mails can provide greater efficiency and productivity than in-person visits to a self-help group.

There is a paucity of empirical data that assesses the efficacy and feasibility of online therapy for clinical applications. To date, the limited studies carried out (mostly with very small sample sizes) have focussed on patient and provider satisfaction with the technology rather than the effectiveness of the technology in delivering services. ${ }^{20}$ Future research should address the following areas (all of which could involve addiction research):

- The differential effects of various online therapeutic interventions among clinical populations. There would be great benefit from learning much more about counseling versus online peer-support groups and so forth.

- The effect online therapy has on therapeutic relationships. This is a critical issue. Ferguson ${ }^{21}$ has eloquently predicted a social revolution in the roles of patient and caregiver; such relationships will be much more equal in future with the therapist being more of a coach to a much more informed consumer.

- Whether providers and consumers find online therapy interventions accessible and desirable.

- Do demographic characteristics (like socio-economic status, ethnicity, culture, geographic location, age and gender) affect a patient's access to and acceptance of online therapy and if so, how and why? The same questions could also be applied to therapists regarding their acceptance and receptivity. Miller ${ }^{22}$ has written about how positive expectancies of therapists have contributed to improved patient outcomes. If clinicians do not believe in online help but were forced to provide it by their employer, would this be subtly communicated to the clients and their treatment undermined?

This paper has demonstrated a need for evaluative research regarding online therapy, particularly since there is a lack of an evidence-base to govern this growing practice. Furthermore, papers like this aim to help to engage consciousness-raising activities and thereby alert clinicians to the future possibilities of practice behavior. After all, clinicians have been constantly striving to better serve their clients from the earliest days of mental health practice. It seems apparent that the Internet and computer-mediated communication are here to stay. Therefore, there is a need to focus on exactly 
how these innovations will impact on our field keeping clients' best interests in mind.

\section{REFERENCES}

1. Segall, R. (2000). Online shrinks: The inside story. Psychology Today May/June:38-43.

2. Parks, M.R., \& Floyd, K. (1996). Making friends in cyberspace. Journal of Communication 46:80-97.

3. Sanders, P., \& Rosenfield, M. (1998). Counselling at a distance: challenges and new initiatives. British Journal of Guidance and Counseling 26:5-10.

4. Griffiths, M.D. (2001). Online therapy: a cause for concern? The Psychologist 14:244-248.

5. Bloom, W.J. (1998). The ethical practice of WebCounseling. British Journal of Guidance and Counselling 26:53-59.

6. Tait, A. (1999). Face-to-face and at distance: the mediation of guidance and counselling through the new technologies. British Journal of Guidance and Counselling 27:113-122.

7. King, S.A., Engi, S., \& Poulos, S.T. (1998). Using the Internet to assist family therapy. British Journal of Guidance and Counseling 26:43-52.

8. Oravec, J.A. (2000). Internet and computer technology hazards: perspectives for family counselling. British Journal of Guidance and Counselling 28:309-324.

9. Cohen, G.E., \& Kerr, A.B. (1998). Computer-mediated counseling: an empirical study of a new mental health treatment. Computers in Human Services 15:13-27.

10. Klein, B., \& Richards, J.C. (2001). A brief Internetbased treatment for panic disorder. Behavioural and Cognitive Psychotherapy 29:113-117.

11. Celio, A.A., Winzelberg, A.J., Wilfley, D.E., et al. (2000). Reducing risk factors for eating disorders: comparison of an Internet and a classroom-delivered psychoeducational program. Journal of Consulting $\mathcal{E}$ Clinical Psychology 68:650-657.

12. Robinson, P.H., \& Serafety, M.A. (2001). The use of e-mail in the identification bulimia nervosa and its treatment. European Eating Disorders Review 9: 182-193.

13. Tate, D.F., Wing, R.R., \& Winett, R.A. (2001). Using Internet technology to deliver a behavioral weight loss program. Journal of the American Medical Association 285:1172-1177.
14. Zabinski, M.F., Pung, M.A., Wilfley, D.E., et al. (2001). Reducing risk factors for eating disorders: targeting at-risk women with computerized psychoeducational program. International Journal of Eating Disorders 29:401-408.

15. Lange, A., Van De Ven, J.-P.Q.R., Schrieken, B.A.L., et al. (2000). Internet-mediated, protocol-driven treatment of psychological dysfunction. Journal of Telemedicine and Telecare 6:15-21.

16. Stroem, L., Pattersson, R., \& Andersson, G. (2000). A controlled trial of recurrent headache conducted via the Internet. Journal of Consulting and Clinical Psychology 68:722-727.

17. Rabasca, L. (2000). Self-help sites: a blessing or a bane? APA Monitor on Psychology 31:28-30.

18. Joinson, A. (1998). Causes and implications of disinhibited behavior on the Internet. In: Gackenbach, J. (ed.), Psychology and the Internet: intrapersonal, interpersonal, and transpersonal implications. New York: Academic Press, pp. 43-60.

19. Cooper, G. (2001). Online assistance for problem gamblers: an examination of participant characteristics and the role of stigma [Doctoral dissertation]. Toronto: Ontario Institute for Studies in Education/University of Toronto. Available: <www.problemgambling.ca/ Results.htm>.

20. Foxhall, K. (2000). How will the rules on telehealth be written? APA Monitor on Psychology 31:38.

21. Ferguson, T. (1996). Health online. Reading, MA: Addison-Wesley.

22. Miller, W.R. (1989). Increasing motivation for change. In: Hester, R.K., Miller, W.R. (eds.), Handbook of alcoholism treatment approaches. New York: Pergamon Press, pp. 67-80.

23. Connall, J. (2000). At your fingertips: five online options. Psychology Today May/June:40.

Address reprint requests to: Dr. Mark Griffiths Psychology Division Nottingham Trent University Burton Street Nottingham, NG1 4BU, UK.

E-mail:mark.griffiths@ntu.ac.uk 